\title{
El castillo palacio de los Álvarez de Toledo en Alba de Tormes*
}

\author{
Herbert GonZÁLEZ ZYMLA \\ Departamento de Historia del Arte I (Medieval) \\ Universidad Complutense de Madrid \\ hgonzale@pdi.ucm.es
}

\section{RESUMEN}

El ascenso político de la familia Álvarez de Toledo, Duques de Alba desde 1472, transformó la villa de Alba de Tormes en capital de una serie de estados señoriales. Como consecuencia de ello, su castillo, hasta entonces un simple emplazamiento militar geoestratégico, se convirtió, sin perder sus funciones militares, en un palacio residencial, adaptado a los nuevos usos protocolarios y cortesanos de finales de la Baja Edad Media. El presente trabajo aborda el análisis de las fases constructivas del edificio durante el siglo XV, es decir, en el tiempo en que Alba de Tormes estuvo gobernada por el obispo Gutierre Álvarez de Toledo (1376-1446); Fernán Álvarez de Toledo, I Conde de Alba (h. 1398-1464); García Álvarez de Toledo, I Duque de Alba (?-1488) y Fadrique Álvarez de Toledo, II Duque de Alba (14581531).

Palabras clave: Castillo palacio, familia Álvarez de Toledo, Condes de Alba, Duques de Alba, Juan Guas, Machyn de Garnica, Abdallá el yesero, Juan Carrera, Pasquier Grenier, Juan de Álava, Diego de Frías, Juan de Almansa.

\section{The Castle-Palace of the Álvarez de Toledo's family in Alba de Tormes}

\begin{abstract}
The political rise of the Álvarez de Toledo family, Dukes of Alba since 1472, transformed the town of Alba de Tormes in the capital city of its domains. The castle which had been, so far, a simple geostrategic military site, became a residential palace, without losing its military dimension. The new residence was adapted to the existing new ceremonial needs and court fashions of the Late Middle Ages. This paper addresses the analysis of the construction phases of the castle-palace during the fifteenth century, when Alba de Tormes was ruled by Bishop Gutierre Alvarez de Toledo (1376-1446); Fernan Alvarez de Toledo, $1^{\text {st }}$ Count of Alba (c. 1398-1464); Garcia Alvarez de Toledo, $1^{\text {st }}$ Duke of Alba I (? -1488) and Fadrique Alvarez de Toledo, $2^{\text {nd }}$ Duke of Alba (1458-1531).
\end{abstract}

Key words: Castle-palace, Alvarez de Toledo family, Earls of Alba, Dukes of Alba, Juan Guas Machyn Garnica, Abdullah the plasterer, Juan Carrera, Pasquier Grenier, Juan de Álava, Diego de Frias, Juan de Almansa.

* Este trabajo forma parte del Proyecto I+D+i HAR2009-08901. 
La arquitectura palacial de los señoríos que estuvieron en manos de los Álvarez de Toledo, Duques de Alba desde 1472, está huérfana de un estudio sistemático que aclare su verdadero impacto dentro del marco general de la historia del arte hispánico a lo largo de la Baja Edad Media. El presente trabajo aborda el estudio del castillo palacio de Alba de Tormes, donde estuvo la capital ducal, el edificio emblemático que catalizó la imagen externa de su poder y que fue la más importante de todas sus residencias.

Los Álvarez de Toledo, cuyo escudo estaba compuesto por 15 jaqueles, 8 puntos de plata equipados de 7 de azur, remontaban su origen a don Pedro, Conde de Carrión, hijo del emperador bizantino Isacio Conmeno, que se había establecido en Castilla en 1053 al servicio de Alfonso VI. En 1085 Pedro Paleólogo y sus 4 hijos participaron en la conquista de Toledo y cambiaron su apellido a de Toledo, en gratitud por haber recibido del rey heredades, patrimonios y oficios municipales ${ }^{1}$. A lo largo de los siglos XII y XIII una inteligente política matrimonial les convirtió en señores de Casas, Viveros y Biezma. Su habilidad a la hora de resaltar una zigzagueante fidelidad a la casa real, ayuda a explicar un progresivo ascenso político que culminó en la segunda mitad del siglo XIV. García Álvarez de Toledo (?- h. 1366), había contraído matrimonio con Mencía Tello de Meneses. Tuvo 9 hijos de los que 3 interesan al objeto de nuestro estudio: García Álvarez de Toledo Meneses (1320-1370), Fernando Álvarez de Toledo Meneses (1325-1384) y Gutierre Álvarez de Toledo Meneses, obispo de Palencia (1322?-1389). Desde 1354 se significaron como colaboradores de Pedro I quien, durante la guerra que le enfrentó a su hermano Enrique, les encomendó la defensa de Toledo ${ }^{2}$. A finales de abril de 1366 Enrique de Trastámara y las compañías blancas se dirigieron a Toledo con la intención de forzar su reconocimiento como único monarca de Castilla. Los Álvarez de Toledo negociaron un acuerdo para evitar el asedio y entregar la ciudad sin sufrir represalias. Primero consiguieron garantías de integridad personal: Enrique II nombró al obispo Gutierre notario mayor de Andalucía y miembro del consejo real; confirmó a Fernando en sus oficios y rentas; y por último, entregó a García los señoríos de Valdecorneja y Oropesa, con sus murallas y castillos, y 60.000 maravedíes de tierra cierta, a cambio de renunciar al maestrazgo de Santiago a favor de Gonzalo Mejía ${ }^{3}$. Enrique II fue aclamado Rey de Castilla el 11 de mayo de 1366.

\footnotetext{
1 No hay documentación suficiente para probar si eran de verdad descendientes del emperador de Bizancio. Recientemente se ha trazado un posible origen mozárabe. J. SALAZAR Y ACHA, "Orígenes históricos de un gran linaje”, VV. AA. Los Álvarez de Toledo. Nobleza viva, Valladolid, 1998, pp. 21-53.

2 García recibió de Pedro I, el 7 de enero de 1358, el lugar de Segura y algunos bienes en Plasencia: Archivo de la Casa Ducal de Alba (en adelante abreviado como A.C.D.A.) Carp. 1 y Carp. 343, doc. 7. Desde 18 de diciembre de 1359 fue maestre de la Orden de Santiago. A.C.D.A, Carp. 156, doc. 1; J.M. CALDERÓN ORTEGA, El Ducado de Alba. La evolución histórica, el gobierno y la hacienda de un estado señorial (siglos XIV-XVI), Madrid, 2005, p. 32; L.V. DÍAZ MARTíN, Los oficiales de Pedro I de Castilla, Valladolid, 1975.

3 J.VALDEÓN BARUQUE, Enrique II, Palencia, 1996, p. 24; J.M. CALDERÓNORTEGA, Documentación abulense medieval en el Archivo de los Duques de Alba, Ávila, 2000, pp. 19-22; y H. GONZÁLEZ ZYMLA, "Arquitectura militar y urbanismo de frontera en Barco de Ávila", Revista de Arqueología, 358 (2011), pp. 32- 43 .
} 
Tras la muerte de Pedro I, los Álvarez de Toledo recibieron de Enrique II importantes recompensas: Valdecorneja y Oropesa ${ }^{4}$. La importancia de Valdecorneja radicaba en tener el control del puerto de Tornavacas, que era el paso natural de los ganados trashumantes por la cañada leonesa, y ser Oropesa paso obligado para quienes iban a la feria de Talavera ${ }^{5}$. Tras la muerte del I señor de Valdecorneja, según un documento ratificado por el Rey en Medina del Campo el 21 de marzo de 1370, la unidad señorial fue segregada ${ }^{6}$. Oropesa, Jarandilla, Tornavacas y Cabañas fueron heredados por los hijos legitimados de García y Valdecorneja pasó a su hermano Fernando, tutor y administrador de todo durante la minoridad de sus sobrinos. Desde entonces, Oropesa y Valdecorneja tuvieron una evolución histórica diferente. Fernando, II señor de Valdecorneja, fijó la capital señorial en Piedrahita, donde mandó construir un alcázar conocido sólo a través de documentos. Fernando tuvo un destacado papel político y militar en el reinado de Juan I. Casó con Leonor de Ayala y Álvarez de Ceballos (hermana del Canciller Pero López de Ayala) y tuvo 6 hijos de los que interesan García Álvarez de Toledo Ayala (?-1408), que le sucedió como III señor de Valdecorneja, y el obispo Gutierre Álvarez de Toledo Ayala (1374-1446). El III señor de Valdecorneja contrajo matrimonio con Constanza Sarmiento, con quien tuvo a Fernando Álvarez de Toledo Sarmiento, IV señor de Valdecorneja (1398-1464).

Gutierre Álvarez de Toledo Ayala, hombre de gran coraçon, muy osado e atrevido, fue doctor en decretos por la Universidad de Salamanca, arcediano de Guadalajara, obispo de Palencia de 1423 a 1439, canciller mayor de la reina Leonor, arzobispo de Sevilla de 1439 a 1442 y primado de Toledo de 1442 a 1446, fecha en que se documenta su muerte en Talavera de la Reina ${ }^{7}$. Desde la década de 1420, introdujo en la corte a su sobrino Fernando, IV señor de Valdecorneja. Gutierre representaba la inteligencia y la capacidad de maniobra política, mientras Fernando, hábil en el arte de la guerra, pudo dedicarse a la carrera militar con la tranquilidad de saber que su tío cuidaba en la corte de los intereses temporales de ambos. Sus proezas afianzaron el prestigio del linaje. Aunque en 1420 eran partidarios de Fernando de Antequera, a partir de 1428 se alinearon con Álvaro de Luna. La derrota de los infantes de Aragón significó importantes recompensas. En 1429 Gutierre recibió: Alba e su tierra e termino e jurisdicción e justicia çevil e criminal, alta e baxa, e mero e mixto imperio ${ }^{8}$.

4 García, I señor de Valdecorneja, obtuvo Cabañas el 4 de abril de 1369, Jarandilla y Tornavacas el 6 de junio de 1369, Horcajo y la legitimidad de sus hijos naturales el 8 de junio de 1369. El obispo Gutierre fue promocionado a la sede ovetense y a Cardenal. A. C. D. A., carp. 198, doc. 24; Archivo Histórico Nacional (en adelante A.H.N.) Consejos, leg. 34.621; A.H.N. Nobleza, Frías, leg. 1362, doc. 4.

5 Enrique II les concedió el control de una serie de castillos, puentes y caminos, cuyos peajes y pontajes generaban pingües rentas. Se trata de una unidad geo-económica y climática homogénea a ambos lados del Sistema Central, en las provincias de Ávila, Salamanca, Toledo y Cáceres. Globalmente examinado, coincide con los territorios ganaderos poblados por vacceos y vetones en la Edad del Hierro.

6 A.C.D.A., carp. 156, doc. 62; y J.M. CALDERÓN ORTEGA, op. cit. 2005, p. 38.

7 Inició su carrera eclesiástica bajo la protección de su tío, el homónimo Cardenal Gutierre, con quien se le ha confundido. A. VACA LORENZO, Catálogo de la documentación medieval del archivo de la casa de Alba relativa a la actual provincia de Salamanca, Salamanca, 1987, p. 22; y J.M. NIETO SORIA, Caída y ascenso de Gutierre Álvarez de Toledo, señor de Alba (1376-1446), Madrid, 2006.

8 A.D.C.A., Biblioteca Palacio de Liria, vitrina 20; J. M. CALDERÓN ORTEGA, "Privilegio rodado de Juan II de Castilla", El legado de la casa de Alba, Madrid, 2013, pp. 264-265. 
Gutierre tomó posesión de Alba de Tormes el 4 de marzo de 1430 y comprendió pronto que su posición tenía mayor valor estratégico que Piedrahita. Diseñó una política arquitectónica encaminada a consolidar sus dominios con independencia de la orientación política del poder real, usando una triple directriz: Transformar los antiguos castillos reales y torreones de vigilancia en residencias fortificadas y autónomas. Proteger con murallas villas y puentes. Financiar la construcción de parroquias, colegiatas, monasterios y hospitales, para escenificar ante sus súbditos su creciente poder y ganarse el favor de las autoridades diocesanas de Ávila, Salamanca, Plasencia y Toledo. En Alba de Tormes, esto se tradujo en un conjunto de obras en el castillo de Tormes, documentadas desde 1429, en la transformación del convento de premostratenses de San Leonardo en convento de Jerónimos en 1442 y en la fundación del Hospital de Santiago en $1445^{9}$.

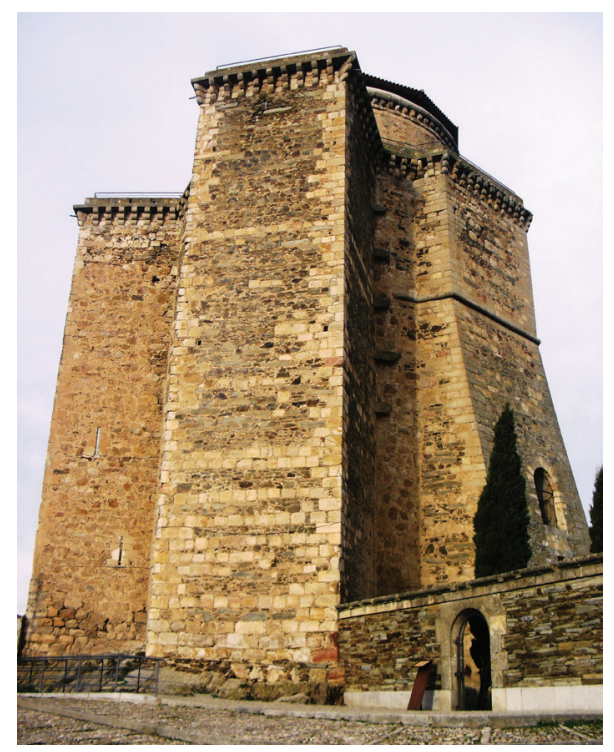

Fig. 1. Torre del obispo Don Gutierre, Castillo de Alba de Tormes, vista desde el lado nororiental, construida a comienzos del siglo XV y reforzada en el XVI.

Hay que imaginar el primitivo alcázar de Alba de Tormes como un edificio cuyas estructuras defensivas del siglo XII habrían obligado a continuos reparos, hechos al compás de los conflictos para adaptarlo a los cambiantes usos militares. Don Gutierre mantuvo el alcázar y yuxtapuso al lienzo suroriental una torre cilíndrica que, con su rotundo volumen, domina la visibilidad del valle del Tormes. Era edificio ignífugo,

9 M. POZA YAGÜE, "La capilla mayor del Monasterio de San Leonardo de Alba de Tormes, panteón funerario de los Álvarez de Toledo, precisiones acerca de su estructura", La Orden de San Jerónimo y sus monasterios. Actas del II simposio, Sevilla, 1999, v. I, pp. 339-357; y F. DE ARAUJO, Guía históricodescriptiva de Alba de Tórmes, Salamanca, 1882, pp. 215-219. 
fabricado en sillarejo mampuesto de pizarras y calizas, canteadas y unidas con argamasa de cal hidráulica.

Aunque nunca se ha hecho un análisis completo de los paramentos murales, a simple vista se advierten importantes reparaciones del siglo XVI y en 1960. En tiempos del obispo Gutierre, la torre se organizó en cuatro plantas de altura. La primera estaba macizada y mide algo más de $2 \mathrm{~m}$. de altura, cosa común a otros edificios militares, que obedece a la necesidad de garantizar que pueda soportar impactos de arietes, catapultas y artillería primitiva. Las tres plantas superpuestas tenían, cada una, sección circular de $11 \mathrm{~m}$. de diámetro, espesor de muro de algo más de $4 \mathrm{~m}$. y una altura total de más de $18 \mathrm{~m}$., lo que la convertía en una torre imponente. La segunda planta tiene machón cilíndrico central de piedra, muy recio para soportar el peso de una bóveda de cañón anular. Dentro del machón se integró la escalera de caracol. La tercera y cuarta plantas debieron separarse con alfarjes de madera que han dejado en los muros mechinales. Las techumbres de madera se sustituyeron en el siglo XVI por cúpulas de media naranja en later de tradición clásica, factura renacentista y apariencia italianizante. La cúpula de la tercera planta se conserva bien, pero la de la cuarta, que servía de apoyo al camino de ronda, se desplomó en el siglo XIX. Ambas salas eran, respectivamente, la armería y la alcoba episcopal ${ }^{10}$.

En fecha indeterminada del siglo XV se yuxtapuso en el lado meridional del cilindro una escalera cuya caja se ajusta a planta cuadrada con machón central de sección cuadrada, en solución cercana a los alminares, permitiendo enroscar los peldaños, apoyados en arcos de medio punto, con tramos de rellano en los giros. Todas las puertas y ventanas son vanos de medio punto o arcos rebajados con centro de dovelaje en el umbral. Los sillares de esquinazos, puertas y ventanas tienen las mismas marcas de cantería, lo que parece indicar que todo fue construido en campañas sucesivas por los mismos operarios. Se coronó con cuerpo de matacanes y ménsulas voladas en triple semicírculo, solución común a la que encontramos en los castillos de Barco de Ávila y Oropesa. Pudo tener cadalso de madera.

La fidelidad de Gutierre y Fernando a Juan II quedó comprometida tras la batalla de Higueruela. Entre 1431 y 1432 estuvieron encarcelados, acusados de conspirar contra Álvaro de Luna, pero no se pudo probar nada y fueron absueltos. Gutierre se retiró de la vida política y centró sus esfuerzos en Alba. A esta época deben corresponder la mayor parte de las obras de la torre. Fernando se reintegró a la vida militar. Desde 1433 fue capitán mayor frontero de Jaén. Allí se documentan importantes victorias sobre los musulmanes que explican la concesión de 3 mercedes: El quinto de las presas que correspondían a Juan II, permiso para exhibir en su escudo una orla con un máximo de 13 banderas arrebatadas a los enemigos y la concesión, el 25 de diciembre de 1439, del título de I Conde de Alba. El papel de Fernando y de Gutierre fue clave en el conflicto de los Infantes de Aragón. La batalla de Olmedo, el 19 de mayo de 1445, supuso la definitiva derrota de los infantes de Aragón y el fin de sus aspiraciones territoriales en Castilla. Culminaba así el proceso de señorialización

10 J. ESPINOSA DE LOS MONTEROS y L. MARTÍN-ARTAJO SARACHO, Corpus de castillos medievales de Castilla, Bilbao, 1974; y E. COOPER, Castillos señoriales en la corona de Castilla, Salamanca, 1991, v. I. 2, p. 429. 
de Alba de Tormes en manos de los Álvarez de Toledo. El testamento del obispo Gutierre, dado el 22 de febrero de 1446, convirtió a Fernando en señor de Alba de Tormes, Alcaraz y Torrejón de Velasco.

Tras la muerte del obispo Gutierre, Fernando cambió de bando y se alió con los enemigos de Álvaro de Luna. El I Conde de Alba, casado con Mencía Carrillo, tuvo 5 hijos. El primogénito, García Álvarez de Toledo Carrillo casó con María Enríquez, hija de Fadrique Enríquez de Mendoza, I Almirante de Castilla, y hermana de Juana Enríquez quien, por su matrimonio con Juan II de Aragón, fue madre de Fernando el Católico. A la larga, esta alianza táctica fue una de las claves que explican el ascenso político de los Alba, puesto que los descendientes de García eran primos hermanos de Fernando el Católico. La primera consecuencia de esta alianza, sin embargo, fue negativa. El I Conde cayó en desgracia y fue encarcelado en Segovia, Roa y Toledo y sus señoríos, juros y oficios fueron secuestrados ${ }^{11}$. El 2 de junio de 1453 fue ejecutado Don Álvaro de Luna y poco después, tras la muerte de Juan II, Enrique IV, en documento dado en el monasterio de Armedilla el 10 de septiembre de 1454, perdonó al I Conde de Alba y mandó restituirle la mayor parte de sus dominios, exceptuando las fortalezas de Alba de Tormes, Barco de Ávila y Torrejón, expresamente retenidas por tres años para comprobar su fidelidad. Fernando volvió a la vida política y bélica, centrando sus esfuerzos en recuperar los patrimonios que le habían sido enajenados ${ }^{12}$.

García Álvarez de Toledo Carrillo, su sucesor, continuó en el bando nobiliario proaragonés, alineado con el arzobispo Carrillo, si bien sus relaciones con el marqués de Villena, el nuevo valido, fueron buenas. En 1465, Enrique IV se reunió con la nobleza en Madrid, con el objeto de volver al gobierno tal y como estaba en 1457. El Rey viajó a Salamanca para ganarse el apoyo de García, llevándole amplias concesiones: la recuperación de Granadilla y la entrega de las villas de Carpio y Abadía. En los cuatro días que duraron los parlamentos, García arrancó del Rey: dar olvido a todas las cosas pasadas, a cambio de recuperar servicios de fidelildad.

Desde 1466, García figuró entre los nobles que apoyaban a la Beltraneja, a cambio de los señoríos de Plasencia y Ciudad Rodrigo. Sin embargo, la firma de la paz de 1470 impidió a Enrique IV cumplir su palabra, dado que el acuerdo de 1466 implicaba desposeer de aquellos lugares a los titulares que ejercían su señorío. Se frustraba así el verdadero objetivo de García, que no era otro sino controlar las cañadas trashumantes que unían León y Extremadura. Para evitar la frustración total de sus aspiraciones, Enrique IV le compensó en 1470 con el marquesado de Coria y, en fecha posterior a agosto de 1472, con el título de I Duque de Alba, lo que equivalía a instalarle en la cúspide de la jerarquía nobiliaria, con la declarada intención de ganarle para la causa de la princesa Juana ${ }^{13}$. A partir de esa fecha, el escudo se surmontó con corona ducal. García murió el 20 de julio de 1488.

En ese inestable contexto político, los castillos y sus torres de homenaje se convirtieron en símbolos del poder emergente de la nobleza. Es entonces cuando se

11 J.M. CALDERÓN ORTEGA, "Los riesgos de la política en el siglo XV: la prisión del Conde de Alba (1448-1454)", Historia, Instituciones y documentos, 21 (1994), pp. 41-62.

12 A.C.D.A., C. 126-26 (45); y A. VACA LORENZO, op. cit. 1987, p. 30.

13 A.C.D.A., C. 292-1 (50); A.C.D.A., C. 317-13 (46); y A. VACA LORENZO, op. cit. 1987, p. 32. 
documenta la segunda fase constructiva del castillo de Alba de Tormes que, a nuestro juicio, es la que de verdad supuso una transformación del castillo en palacio. No está del todo claro si se aprovecharon los cimientos del edificio anterior o si se optó por hacer un edificio de nueva planta, lo que parece más probable, aprovechando materiales constructivos anteriores. Se yuxtapuso a la torre de Don Gutierre un edificio nuevo cuya planta responde a un tipo muy habitual en la arquitectura militar del siglo XV, asociada a la señorialización de Ávila, Segovia, Salamanca, Toledo y Cáceres. Comparte, como es lógico, rasgos formales idénticos a los de otros castillos palacio que estuvieron en manos de los Álvarez de Toledo: Barco de Ávila, Oropesa, Castronuevo, Jarandilla, etc. y a edificios militares de tiempos de Enrique IV, especialmente aquellos, en manos de otras familias nobiliarias, que estaban ubicados en la misma región: Arenas de San Pedro, Mombeltrán, Bonilla de la Sierra, Villatoro y Béjar.

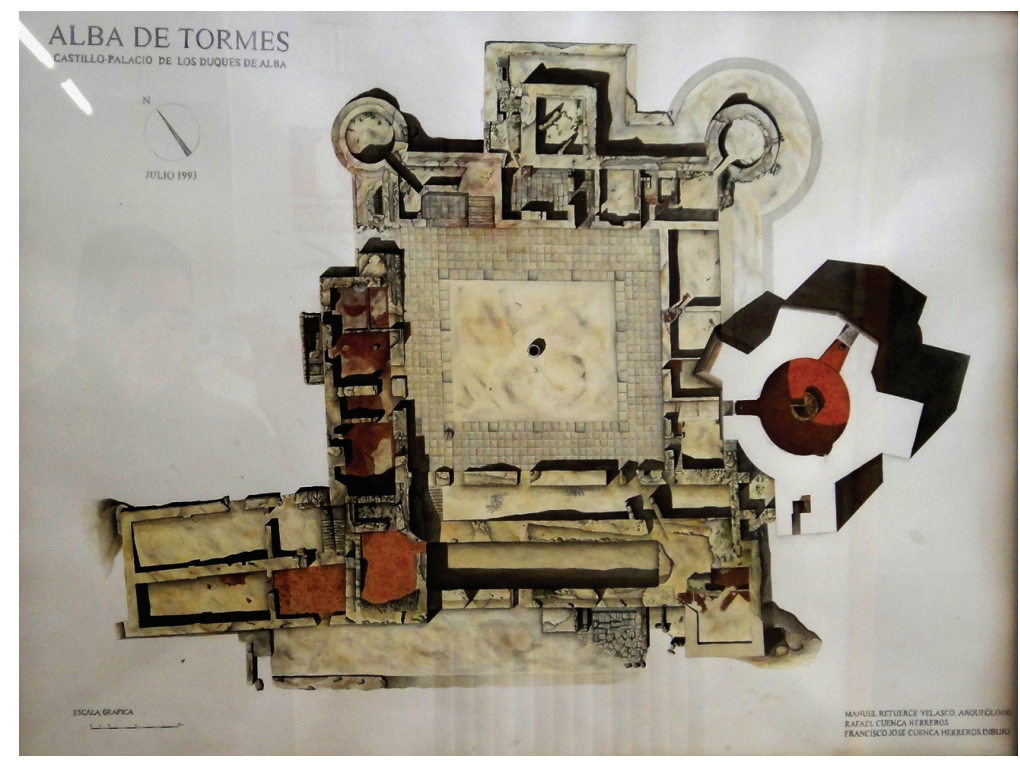

Fig. 2. Plano arqueológico, dibujado por Manuel Retuerce Velasco, Rafael Cuenca Herreros y Francisco José Cuenca Herreros, 1991, Museo de Salamanca.

El castillo de Alba de Tormes se asienta directamente sobre la roca madre de pizarra. Hasta 1992, las publicaciones se limitan a describir la torre de Don Gutierre, a veces llamada: torre Blanca, por ser lo único que quedó visible. Las excavaciones, hechas entre junio y diciembre de 1991, pusieron al descubierto un edificio de planta cuadrada que, a juzgar por las estampas del siglo XIX que lo representan en ruinas, debía tener una longitud de lado casi idéntica a su altura ${ }^{14}$. Desde lejos tenía la

14 M. RETUERCE VELASCO, "El Castillo de Alba de Tormes: primeros resultados arqueológicos", Boletín de Amigos del Museo de Salamanca, (1992), p. 21. 
apariencia de un cubo flanqueado por cuatro torreones cilíndricos en los extremos, con tres potentes torres, la ya comentada de Don Gutierre y dos de sección cuadrada, más grandes que las cilindras de los esquinazos, pero más pequeñas que la de Don Gutierre, abiertas en el centro de los paramentos nororiental y noroccidental. Como otros castillos del siglo XV disponía de barbacana o parapeto defensivo en el área noroccidental.

La planta, dada a conocer por Retuerce, constaba de un patio central de sección cuadrada, dotado de crujías, en torno al que se distribuían las habitaciones y sectores residenciales. La excavación puso al descubierto un aljibe central para recoger agua de lluvia de notable capacidad y sección rectangular, en su día cubierto con bóveda de cañón. Estaba dotado de un brocal de pozo de sección octogonal labrado en granito, que siempre estuvo visible en superficie, señalando al inicio de la excavación, dónde estaba el centro geométrico del patio de armas. Las excavaciones también pusieron al descubierto algunos acondicionamientos de ingeniería hidráulica, pensados para evacuar las aguas fecales que, añadidos a la existencia de restos de un tiro de chimenea y al descubrimiento de piedras de moler, permitieron ubicar la cocina en la panda norte, entre la monumental escalera de protocolo y una escalera de servicio. En todo el yacimiento se han recuperado fragmentos cerámicos de platos y escudillas vidriados en blanco, azul y verde, así como botones, restos de recipientes de vidrio... Existe un segundo aljibe, desplazado hacia la panda meridional, aún no excavado, del que se tiene localizada la boca de acceso en una pared, enlucida de rojo cinabrio.

La data de las obras ha de ser posterior a 1454 por haberse encontrado durante la excavación una blanca acuñada por Enrique IV en la ceca de Cuenca. Los gastos de algunas reformas están recogidos, aunque sin especificar qué era lo que se construía, en el Libro maestro del Estado de Alba. Allí figuran los nombres de los maestros que supervisaban las empresas artísticas de los Duques. El primer pago apuntado data del 22 abril de 1473 y el último del 2 de julio de 1479. La suma total de los gastos de construcción ascendió a 377.325 maravedíes, lo que supone, sin duda, una transformación radical del castillo. Algunos datos son reveladores. En 1473 está documentado el maestro Tomás, de origen bretón, que entró al servicio de los Alba para construir las cavas del castillo de Coria, cobrando un sueldo de 30 doblas, 1 librea y 20 maravedíes diarios de mantenimiento, con la obligación de asumir todas las obras que le encargasen ${ }^{15}$.

Entre 1473 y 1479 se conocen pagos a Machyn de Garnica, que debe ser Machyn cantero, veçino de Salamanca; a él se debe la construcción de las caballerizas, cobradas en abril de $1474^{16}$. En abril de 1479 consta el trabajo de un maestro yesero llamado Abdalla, que cobraba 1.500 maravedíes y 30 fanegas de trigo, así como una cantidad variable por cada día de trabajo en las obras del palacio que, en 1479, ascendió a 90 maravedíes ${ }^{17}$. Por entonces se debía trabajar en la decoración de los interiores y lo

15 A.C.D.A., Libro maestro del Estado de Alba, C. 301, 40; y J M. CALDERÓN ORTEGA, op. cit. 2005, p. 279.

16 A.C.D.A., Libro maestro del Estado de Alba, C. 301, 113 y 339; y E. COOPER, op. cit. 1991, vol. I.2, p. 429.

17 A.C.D.A., Libro maestro del Estado de Alba, C.301, 184 y 1158. 
más probable es que Abdalá fuera entallador de yesos. La terminación de las obras implicó el solado de los salones, que fue contratado por Juan de Sevilla, vecino de Toledo, en 1479, con un sueldo de 1.800 maravedíes por cada 1.000 ladrillos que colocara, especificando que se le daría sólo cal, agua y capachos ${ }^{18}$. Las excavaciones han permitido recuperar pavimentos completos y azulejería de tipo nazarí del siglo $\mathrm{XV}$, coherentes con lo que conocemos en otros conjuntos palaciales contemporáneos. Seguro que había zócalos de azulejería y paramentos murales de filigrana flamígera o de lacería musulmana tallada en yeso polícromo ${ }^{19}$. También se ha documentado la presencia de otros maestros de obras: en 1482 Juan Carrera y en 1487 Martín Caballero $^{20}$.

No menos importantes fueron los gastos, entre 1474 y 1479, relacionados con la construcción de una residencia suburbana, hoy imposible de localizar, llamada: Huerta de la Alhondiga, dotada de un paseo de 500 pies, plantado de álamos y sauces. Tenía tapias, huerta y noria para elevar el agua, lo que sugiere estar en las cercanías del Tormes ${ }^{21}$.

El Libro Maestro permite saber algo sobre los ornatos que había en los salones, decorados con tapices, que, además del valor decorativo, hacían más cálidos los interiores. En 1473 consta la compra de paños y tapices, dos desarrollando la historia de Jaffé, a Pedro García de Medina y a su hijo Álvaro, mercaderes de Medina del Campo, por 110.000 maravedíes. Teniendo en cuenta su temática iconográfica, Jefté el galaadita, sucesor de Abimelec (hijo de Gedeón) y la cronología de la compra, deberíamos identificarlos como una réplica parcial de la serie de colgaduras tejidas hacia 1470 en Tournai por Pasquier Grenier para el duque de Borgoña Felipe el Bueno. En 1474 consta que fueron entregados 160.000 maravedíes a dos agentes que tenían que viajar a Flandes para comprar tapices. Regresaron en 1475 con cuatro paños de cama con la sobrecama, cuatro paños de sala, el dosel rico y otro dosel de raso. En 1486 consta la existencia de un oficial, llamado Pedro González, repostero de tapicería, que percibía 6.000 maravedíes de quita y 500 de jornal de veinticinco peones para sacudir y emparamentar tapicerías y alfombras. La creciente importancia del protocolo explica los gastos en telas y sastres para confeccionar ricos vestidos, así como gastos en compra de pieles para confeccionar abrigos ${ }^{22}$.

18 A.C.D.A., Libro maestro del Estado de Alba, C.301, 1157;y M. RETUERCE VELASCO y A. TURINA GÓMEZ, "Azulejos procedentes del Castillo Palacio de los Duques de Alba", La ceramique médiévale en Mediterranée, Aix en Porvence, 1997, pp. 615-626.

19 El 13 de abril de 1479: escrivio el duque my señor al alcayde Diego de Villapecellín que, cada dia que el dicho maestre Abdallá labrare en el alcaçar de Alva, le de tres rreales para su rropa e mantenymiento. A.C.D.A., Libro maestro del Estado de Alba, C.301, p. 157; y E. COOPER, op. cit. 1991, p. 429.

20 Trabajó en los castillos de Coria y San Felices de Gallegos. E. COOPER, op. cit. 1991, p. 52; A.C.D.A., C. 157, 38; y J.M. CALDERÓN ORTEGA, op. cit. 2005, p. 280.

21 Tenía un hortelano, llamado Diego Fernández de Carrión, que debía cuidar del jardín y los pavos del Duque, así como del servicio de la mesa. A.C.D.A., Libro maestro del Estado de Alba, C.301, 1123-5.

22 Consta la compra de 900 martas cibelinas en 1477 por 1.360 maravedíes. En 1479 se compraron brocados verde rico o de pelo, por 9.250 maravedíes la vara. Se registran brocados de todos los colores, terciopelos, rasos, aceituníes, fustanes de Brujas, Londres y Ruán, cordobanes, etc. En la década de 1480 el sastre se llamaba Jaques y en la década de 1490 está documentado Juan Mateos. A.C.D.A., Libro maestro del 


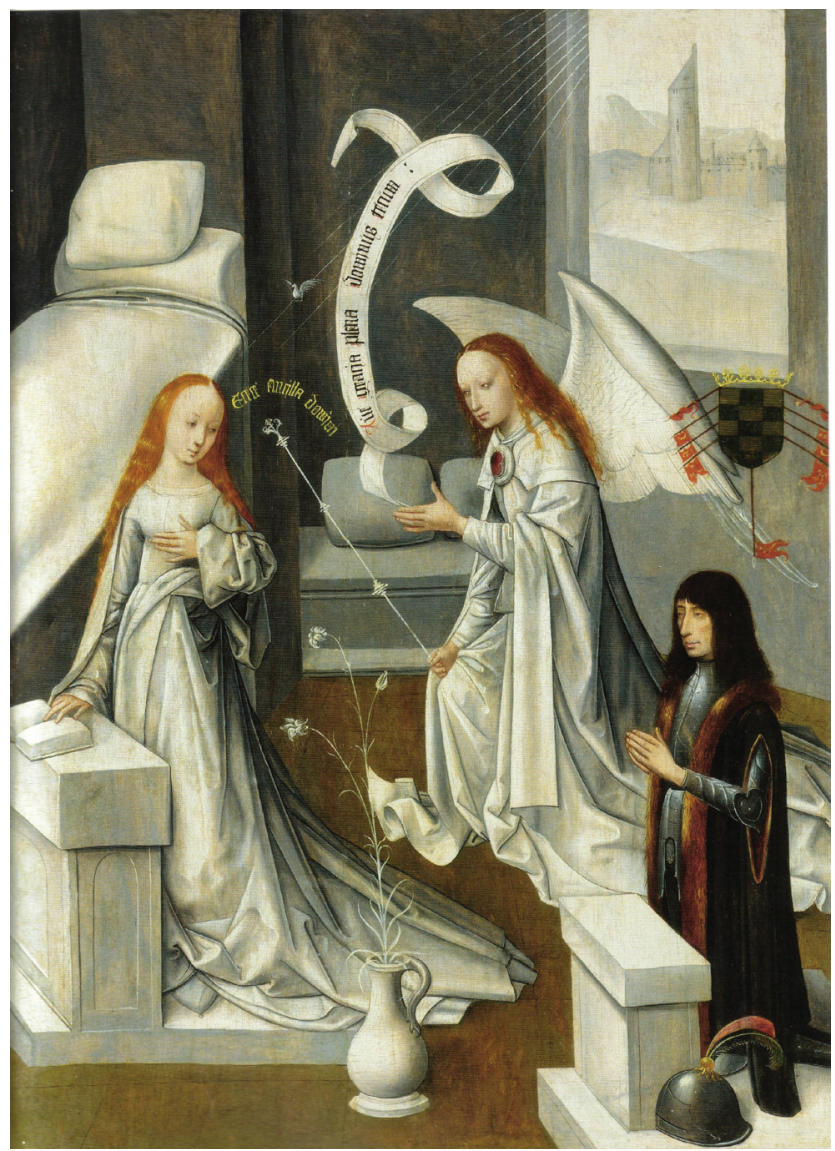

Fig. 3. Anunciación con el I duque de Alba orante, óleo sobre tabla, maestro de la Virgo inter Virgenes, hacia 1472, Fundación Casa de Alba.

La tabla de roble pintada al óleo con la Anunciación, atribuida al maestro de la Virgo inter Virgenes, constituye un documento iconográfico de valor inestimable para estudiar la iconografía del I Duque, representado de rodillas sobre un reclinatorio, en actitud orante, levemente girado de tres cuartos, con larga melena de pelo marrón que le cae por la espalda, armadura de placas, abrigo de piel de marta y un morrión con penacho de 2 plumas (roja y verde) a los pies. Al fondo, a través de una ventana, se ve una fortaleza que puede identificarse como el castillo de Alba visto desde los apartamentos del retiro espiritual del monasterio de San Leonardo ${ }^{23}$.

Estado de Alba, C.301, 49, 344, 157 y 561; y L. REAU, Iconografia del arte Cristiano. Antiguo Testamento, Barcelona, 1995, T. I, v. 1, p. 277.

23 D. ANGULO ÍÑIGUEZ, "El maestro de la Virgo inter vírgenes: la tabla del primer conde de Alba", Archivo Español de Arte y Arqueología, II (1925), pp. 193-196; y "Maestro de la Virgo inter vírgenes", El legado Casa de Alba, Madrid, 2012, pp. 118-119. 
El I duque de Alba tuvo 11 hijos. De ellos interesa en nuestro trabajo Fadrique Álvarez de Toledo Enríquez, II duque de Alba (1458-1531) que durante la guerra civil, de 1475 a 1476, encabezó del sector de la aristocracia más adepto a los Reyes Católicos. Durante la guerra con Portugal, el castillo de Alba jugó, como cabeza señorial, un papel importante; Fadrique se mantuvo fiel a la causa de Isabel y atrajo a los Estúñiga. En 1486 Fadrique asumió la capitanía general de la frontera de Granada, con la misión de conservar todo el terreno conquistado. Fue allí donde ganó merecida fama de estratega. Tras la muerte de Isabel I en 1504, Fadrique marchó con Fernando a Nápoles, donde estuvo hasta la muerte de Felipe I. Fue entonces cuando Fernando encomendó a Fadrique anexionar Navarra sin provocar los traumas que una guerra llevaba consigo.

En 1517, habiendo fallecido Cisneros, fue el Duque de Alba el noble que recibió a Carlos I en las cortes de Valladolid, en las que se juró lealtad al rey. Carlos I incorporó a Fadrique a su séquito y éste le acompañó a Barcelona. En 1519, en ocasión del capítulo de la orden del Toisón de Oro, le concedió esta distinción, siendo el primer noble castellano en recibirla y en incorporarla a su escudo, detalle que ayuda a datar algunos de sus mecenazgos. En 1520 le nombró Grande de España. Acompañó a Carlos I a Alemania, Flandes y Bolonia, cuando fue coronado Rey de Romanos el 23 de octubre de 1520. Al iniciarse la revuelta de las comunidades, regresó a Castilla, donde jugó un papel fundamental al evitar que la alta nobleza se levantara en contra el Rey ${ }^{24}$.

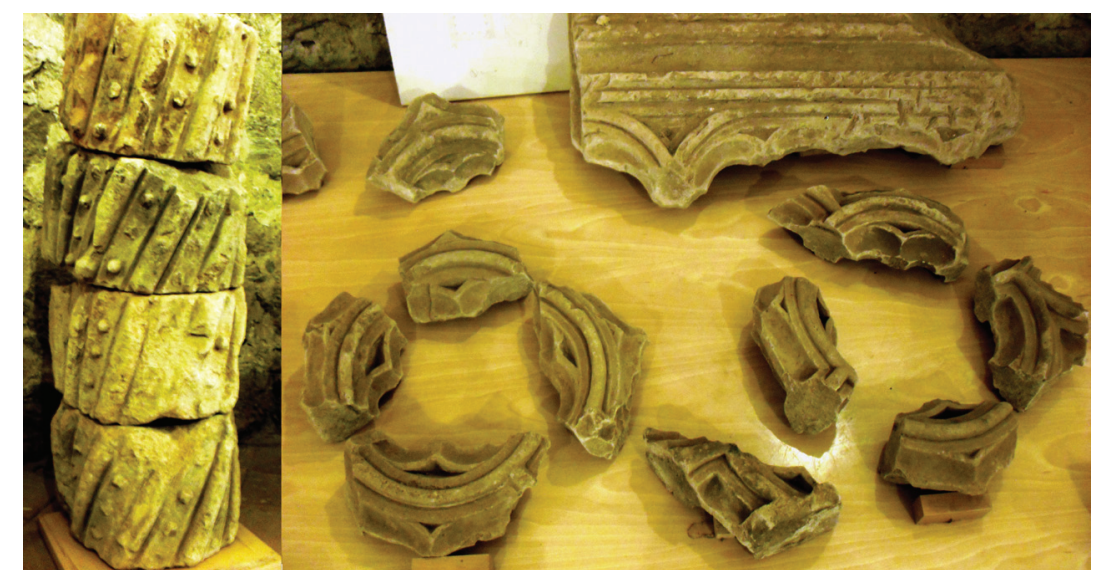

Fig. 4. Pilar torneado con perlas de Ávila y tetralóbulos calados procedentes del patio de armas del castillo de Alba de Tormes, obra probable de Juan Guas, 1493-1494, Parque Arqueológico del Castillo de Alba de Tormes.

24 M.A. LADERO QUESADA, Castilla y la conquista del reino de Granada, Valladolid, $1967 ; \mathrm{L}$. CORREA y J. YANGUAS Y MIRANDA, Historia de la conquista del Reino de Navarra por el Duque de Alba, general del ejército del rey Fernando el Católico en el año 1512, Valladolid, 2005; y S. FERNÁNDEZ CONTI, "Álvarez de Toledo, Fadrique (II Duque de Alba)", VV. AA., La Corte de Carlos V. Los consejos y los consejeros de Carlos V, Madrid, 2000, pp. 32-33. 
Al gobierno del II Duque corresponden algunas obras importantes en el castillo palacio de Alba. En la documentación están citados como maestros de obras Enrique Egas en 1491 y Juan Guas entre 1493 y 1494, a quien se adjudican razonablemente las arquerías del patio de $\operatorname{armas}^{25}$. Las excavaciones de 1991 pusieron al descubierto restos materiales de pilares torneados con fustes decorados con perlas de Ávila y parapetos tetrafoliados que, por el lugar donde fueron localizados, deben corresponder al patio y pueden relacionarse formalmente con otras obras de Guas conocidas y bien documentadas, como el patio del Palacio del Infantado de Guadalajara, construido entre 1480 y $1483^{26}$.

En 1502 el II Duque nombró maestro mayor de obras a Fadrique de Arelar, vecino de Valladolid, con unos cometidos muy precisos, enumerados en escritura de contrato, con los que se intentaba centralizar los mecenazgos ducales ${ }^{27}$. El maestro Fadrique fue despedido en 1528, al tiempo que se creaba una nueva figura en los oficiales al servicio del Duque, el veedor de obras, que recayó a partir de 1529 en Juan Trollo, domiciliado en Coria, con sueldo anual de 20.000 maravedíes y tres cahíces de trigo, a lo que se añadía capa y posada ${ }^{28}$.

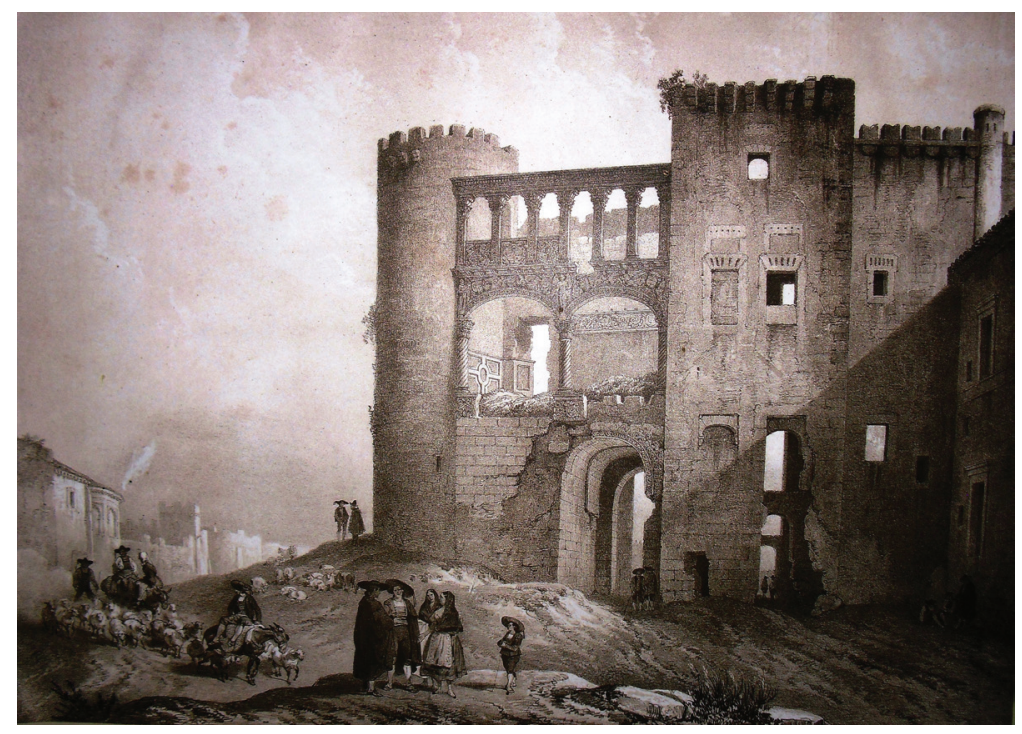

Fig. 5. Estampa realizada a partir de un dibujo de Genaro Pérez Villaamil, que muestra la fachada occidental del castillo de Alba de Tormes, tal y como estaba hacia 1850, Colección particular.

25 J.M. AZCÁRATE RISTORI, "Sentido y significado de la Arquitectura hispanoflamenca en la corte de Isabel la Católica", Boletín del Seminario de Estudios de Arte y Arqueología de la Universidad de Valladolid, XXX, VII (1971), pp. 201-223.

26 A. PONZ, Viaje de España en que se da noticia de las cosas más apreciables y dignas de saberse que hay en ella, Madrid, 1788, Tomo XII, Carta X, pp. 5 y ss.

27 J.M. CALDERÓN ORTEGA, op. cit. 2005, p. 280.

28 A.C.D.A. C. 22, 75; J.M. CALDERÓN ORTEGA, op. cit. 2005, p. 280. 
En 1515 consta que el arquitecto Juan de Álava, importante representante del plateresco salmantino, trabajó al servicio del Duque con un sueldo anual de 10.000 maravedíes. A su actividad debe adjudicarse la reedificación de la fachada noroccidental, donde se ubica la única puerta del castillo, conocida por estampas del siglo XIX. Desde el punto de vista formal, su obra consistió en crear una puerta de protocolo respetando la puerta primitiva. La excavación de 1991 demostró que era una puerta en eje con el patio de armas, descentrada respecto del lienzo de muro para acercarla a la torre del homenaje, con la que forma esquinazo en ángulo de $90^{\circ}$, ganando así inmejorable protección. La potencia de espesor de muro (casi $5 \mathrm{~m}$.) permitía emplazar dos hojas de puerta y quizá rastrillo. El cuerpo bajo de la fachada estaba formado por un zócalo de potentes sillares escuadrados y lisos, con la puerta en arco de medio punto. Sobre él se dispuso un balcón accesible desde la planta noble, en forma de doble arco rebajado, apoyado en tres columnas torneadas de capitel corintio. Coronándolo todo, se levantaba una galería adintelada sobre pilastras de sección cuadrada, capitel corintio y zapatas. La superficie de los parapetos, muros, enjutas, intradós y trasdós de los arcos se aprovechó para labrar fina talla de grutescos, candelieri, con emblemas heráldicos familiares, algunos coronados de capelo, y ángeles tenantes.

En el siglo XVIII ya advirtió Ponz la relación de este balcón de manifestación con el foco plateresco salmantino; y nosotros precisamos, usando la documentación, quizá con Juan de Álava o más probablemente con las obras que se pagaron el 9 de noviembre de 1531, por valor de 30.0000 maravedíes a Diego de Frías y a Juan de Almansa por hacer el balconcillo ${ }^{29}$. Aunque se ha intentado ver la Torre de Don Gutierre como torre de homenaje, los documentos y descripciones del castillo parecen indicar que eran espacios diferentes. Creo que la torre del homenaje era el torreón cuadrado situado en el lienzo occidental, junto a la puerta. Hay argumentos poderosos para hacer esta afirmación: Está cerca de la puerta y ello facilitaría el acceso de los representantes de las villas para hacer el pleito de homenaje, subiendo a la planta noble por la escalera de protocolo, que se ha localizado en el ángulo septentrional del patio. Tenía tiro recto con rellanos en quiebros de $90^{\circ}$ y peldaños labrados en un único bloque de granito. El salón estaría ubicado dentro de la torre, en una solución estructural idéntica a la que describe el profesor Antonio Almagro al hablar del arte hispanomusulmán. Ello nos daría un salón de homenaje ducal en alto, junto a un balcón de manifestaciones, adaptando, a menor escala y sin pretensiones, el protocolo regio a los usos nobiliarios.

Fadrique, II Duque de Alba, casó con Isabel de Zúñiga y tuvo 6 hijos. Su primogénito, García Álvarez de Toledo Zúñiga, casó con Beatriz de Pimentel, hija del conde de Benavente. Fue III marqués de Coria y murió el 29 de agosto de 1510, en el desastre de Gelves. Su viuda, Beatriz, y su padre, el Duque Fadrique, volcaron todos sus esfuerzos en educar a Fernando Álvarez de Toledo Pimentel, el heredero de la casa ducal, nacido en Piedrahita el 29 de octubre de 1507, en quien cifraron todas sus esperanzas. A finales del siglo XV y a principios del XVI podemos hablar

29 A. PONZ, op. cit. 1788, Carta X, p. 5 y ss; A.C.D.A., C. 168, 1, fol. 139; y J.M. CALDERÓN ORTEGA, op. cit. 2005, pp. 281 y 376. 
ya de una esplendente corte cultural, de clara sensibilidad humanista, en Alba de Tormes. En un primer momento, Fadrique encargó la educación del heredero y de sus hermanos, Bernardino, Catalina y María, a fray Severo, monje jerónimo del convento de San Leonardo ${ }^{30}$. Más tarde, hubo un equipo de educadores a la cabeza del cual estuvieron Juan Luis Vives y un humanista benedictino de origen siciliano llamado Bernardo Gentile ${ }^{31}$.

Por la corte ducal de Alba pasaron, protegidos por el Duque Fadrique, Juan Boscán y Almogáver y Garcilaso de la Vega, que residieron en ella largas temporadas. Allí se leyó el Cortesano de Baltasar de Castiglione, traducido al castellano por Boscán ${ }^{32}$, y el De re militari de Vegecio ${ }^{33}$, una lectura clásica importante para entender la formación militar del Gran Duque de Alba. El castillo fue escenario de fiestas cortesanas, lidias de toros para celebrar toda clase de éxitos, y fiestas entendidas a la manera italiana y flamenca ${ }^{34}$. En ese contexto se documenta la primera representación teatral de una obra de Juan del Encina, que estuvo al servicio del Duque entre 1492 y 1496 e hizo la primera compilación del Cancionero general, publicada en 1496, incluyendo la lírica amorosa y cortesana ${ }^{35}$.

El II Duque, Fadrique, murió en Alba de Tormes en 1531, pese a su largo historial militar, Francesillo de Zúñiga le describe: largo de espiritu y corto de grebas, más redondo que una pieza de dos ducados ${ }^{36}$. Con su muerte se cierra el análisis del castillo medieval y con la subida al poder del III Duque, Fernando Álvarez de Toledo y Pimentel, se abre la transformación del edificio en un palacio renacentista cuyo estudio debe abordarse desde unos parámetros de mecenazgo distintos.

30 A. SALCEDO RUIZ, "El ayo y preceptor del Gran Duque de Alba", Revista de Archivos Bibliotecas y Museos, XI (1907), pp. 370-377.

31 J.M. PEÑA Y CÁMARA, "Un cronista desconocido de Carlos V, el humanista siciliano Fray Bernardo Gentile O. P.", Hispania: Revista española de historia, 17 (1944), pp. 536-568.

32 G. DE LA VEGA, Poesías completas, Madrid, 1989. Vid especialmente Égloga I, Égloga II, v. 1038 a 1059 y Elegía I; y B. DE CASTIGLIONE, El Cortesano, Barcelona, 1973.

33 VEGECIO, De re militari, Roma, 1937.

34 J.M. CALDERÓN ORTEGA, op. cit. 2005, p. 382; y J. SUBIRÁ, La música en la casa de Alba, Madrid, 1989.

35 A. BUSTOS, "Sobre la organización del Cancionero General: la huella de Juan del Encina", Estudios sobre el Cancionero General (Valencia, 1511), Valencia, 2012, p. 96.

36 F. de ZÚÑIGA, Crónica burlesca del emperador Carlos V, Salamanca, 1989. 